\title{
Novel Benzodiazepine-Like Ligands with Various Anxiolytic, Antidepressant, or Pro-Cognitive Profiles
}

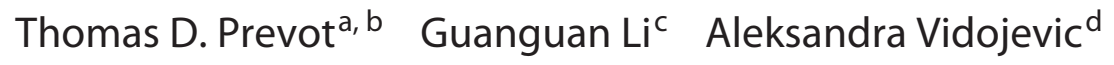 \\ Keith A. Misquitta ${ }^{a, e}$ Corey Fee $^{a, e}$ Anja Santrac $^{d}$ Daniel E. Knutson ${ }^{c}$ \\ Michael Rajesh Stephen ${ }^{c}$ Revathi Kodalic Nicolas M.Zahnc Leggy A. Arnold ${ }^{c}$ \\ Petra Scholze ${ }^{f}$ Janet L. Fisherg Bojan D. Markovićh Mounira Banasra, b, e \\ James M. Cook ${ }^{c}$ Miroslav Savic ${ }^{d}$ Etienne Sibillea, b, e \\ ${ }^{a}$ Campbell Family Mental Health Research Institute of CAMH, Toronto, ON, Canada; ${ }^{b}$ Department of Psychiatry, \\ University of Toronto, Toronto, ON, Canada; ' ${ }^{C}$ Department of Chemistry and Biochemistry, University of Wisconsin- \\ Milwaukee, Milwaukee, WI, USA; ${ }^{d}$ Department of Pharmacology, Faculty of Pharmacy, University of Belgrade, \\ Belgrade, Serbia; ${ }^{e}$ Department of Pharmacology and Toxicology, University of Toronto, Toronto, ON, Canada; \\ ${ }^{f}$ Department of Pathobiology of the Nervous System, Center for Brain Research, Medical University of Vienna, \\ Vienna, Austria; ' Department of Pharmacology, Physiology and Neuroscience, University of South Carolina School \\ of Medicine, Columbia, SC, USA; ${ }^{\text {h}}$ Department of Pharmaceutical Pharmacy, Faculty of Pharmacy, University of \\ Belgrade, Belgrade, Serbia
}

\section{Keywords}

Gamma-aminobutyric acid · GABA · Mood · Benzodiazepine · Cognitive impairment · Behavior · Anxiety · Depression ·

Working memory

\begin{abstract}
Altered gamma-aminobutyric acid (GABA) function is consistently reported in psychiatric disorders, normal aging, and neurodegenerative disorders and reduced function of GABA interneurons is associated with both mood and cognitive symptoms. Benzodiazepines (BZ) have broad anxiolytic, but also sedative, anticonvulsant and amnesic effects, due to nonspecific GABA-A receptor (GABAA-R) targeting. Varying the profile of activity of $B Z s$ at GABAA-Rs is predicted to uncover additional therapeutic potential. We synthesized four novel imidazobenzodiazepine (IBZD) amide ligands and
\end{abstract}

tested them for positive allosteric modulation at multiple a-GABAA-R (a-positive allosteric modulators), pharmacokinetic properties, as well as anxiolytic and antidepressant activities in adult mice. Efficacy at reversing stress-induced or age-related working memory deficits was assessed using a spontaneous alternation task. Diazepam (DZP) was used as a control. Three ligands (GL-II-73, GL-II-74, and GL-II-75) demonstrated adequate brain penetration and showed predictive anxiolytic and antidepressant efficacies. GL-II-73 and GL-II-75 significantly reversed stress-induced and age-related working memory deficits. In contrast, DZP displayed anxiolytic but no antidepressant effects or effects on working memory. We demonstrate distinct profiles of anxiolytic, antidepressant, and/or pro-cognitive activities of newly designed IBZD amide ligands, suggesting novel therapeutic potential for IBZD derivatives in depression and aging.

(c) 2019 S. Karger AG, Basel

\section{KARGER}

(c) 2019 S. Karger AG, Basel

E-Mail karger@karger.com

www.karger.com/mnp
Etienne Sibille, $\mathrm{PhD}$

Campbell Family Mental Health Institute, Centre for Addiction and Mental Health 250 College Street, Room 134

Toronto, ON M5T 1R8 (Canada)

E-Mail Etienne.sibille@camh.ca 


\section{Introduction}

Altered levels and signaling of gamma-aminobutyric acid (GABA), the major inhibitory neurotransmitter, is frequently reported in depression $[1,2]$, anxiety disorder [3], normal ageing [4], and neurodegenerative disorders, including Alzheimer's disease [5], and in multiple brain regions including the prefrontal cortex [6] and anterior cingulate cortex [7]. Recent studies showed that such reductions of GABA levels in the human brain are associated with cognitive impairments in an age-dependent manner [8] and are further worsened during older age [9].

GABA signals through GABA receptors that are represented by two classes: $\mathrm{GABA}_{A}$ and $\mathrm{GABA}_{B}$ receptors. $\mathrm{GABA}_{\mathrm{A}}$ receptors (GABAA-Rs) are composed of multiple subunits $(\alpha, \beta, \gamma, \delta, \varepsilon, \theta, \pi$, and $\rho$ ) assembled into pentamers [10] forming a chloride channel. Benzodiazepines (BZs; such as diazepam, DZP) and imidazobenzodiazepines (IBZDs; such as flumazenil) represent the well-established classes of therapeutics [11] acting on GABAARs [12]. BZs are prescribed to alleviate the burden of anxiety [13] but have debatable efficacy on the core symptoms of depression [14]. BZs modulate GABAA-R activity as non-selective positive allosteric modulators (PAMs), via binding between the $\gamma 2$ and either the $\alpha 1, \alpha 2, \alpha 3$, or $\alpha 5$ subunits [12]. Even though the beneficial effects of BZ seems to be mediated by their complex activity at multiple a subunits, this broad receptor activity contributes to significant side effects (sedation, hypnosis, ataxia, dependence, amnesia) limiting their therapeutic potential. However, the relations are not straightforward; for instance, high activity at a1-GABAA-Rs induces sedation and contributes to amnesia, but the same receptor subtype is also implicated in cognition by co-localizing with $\alpha 5$ and $\gamma 2$ subunits [15]. The BZ anxiolytic properties are mediated predominantly by a2-GABAA-Rs [16] and also by a5-GABAA-Rs $[17,18]$. Selective activity at a5GABAA-Rs has also been suggested to play a critical role in alleviating "behavioral emotionality" (anxiety and depressive-like behaviors) in a mouse model of depression (using chronic stress in mice [19]) or cognitive dysfunctions in mouse models of schizophrenia [20] or in old rats [21]. The a5-GABAA-Rs have predominant distribution in the neocortex and hippocampus [22] suggesting a role in cognition and emotion [17, 23], while a1-GABAA-Rs have ubiquitous distribution and are very abundant [24], potentially explaining their effect on sedation [25] and their controversial role in cognition $[15,26]$.

Novel Benzodiazepine-Like Ligands with Various Profiles
Since BZs have the potential to alleviate multiple crossdiagnostic symptoms, but have limited use because of wide side effects, we developed a series of IBZDs [27] with expected reduced activity at a1-GABAA-R, which could uncover certain pharmacological effects ordinarily not detected with standard BZs. IBZD ligands were designed to fit the a5-GABAA-R pharmacophore/receptor model [27] and here, we describe the synthesis, pharmacokinetic, activities at $\alpha$-GABAA-Rs, and behavioral characteristics of four novel IBZD ligands.

Using tests assessing anxiety- [28] and depressive- [29] like behaviors as well as working memory [30] in mice, we tested the hypothesis that novel IBZD-like ligands maintain the anxiolytic efficacies of BZs and display additional therapeutic efficacies related to GABAergic dysfunctions in human disorders, namely antidepressant potential and pro-cognitive activities. For the purpose of this study, we define pro-cognitive as the efficacy at reversing stress-induced or age-related working memory deficits.

\section{Materials and Methods}

Detailed methods are provided in the online supplements (see www.karger.com/doi/10.1159/000496086 for all online suppl. material).

\section{Chemistry}

Based on an IBZD structure (a BZ-imidazol hybrid), we have previously developed ethyl esters of IBZDs [27]; however, esters are quickly metabolized. Amides are commonly used as replacements to improve metabolic stability and bioavailability [31]. Hence, a series of amide IBZD ligands were designed [32] that fit the pharmacophore/receptor model [27], with similar or increased preferential binding affinity and efficacy at GABAA-Rs, compared to corresponding esters [33]. All four amide ligands, referred herein as GL-II-73, GL-II-74, GL-II-75, and GL-II-76, were prepared from the SH-053-2'F-R-CH3 parent compound following steps described in the online supplementary Methods and online supplementary Figure S1.

\section{Electrophysiological Recordings}

Electrophysiological recordings were performed as described by Alexeev et al. [34] (online supplementary Methods). Briefly, HEK-293T cells were transiently transfected with mammalian clones of GABAA-Rs. Currents in response to GABA and GABA+ modulators $\left(\mathrm{EC}_{3-5} \mathrm{GABA}\right)$ were measured using voltage-clamp recordings in the whole-cell configuration.

\section{Binding Studies}

Binding studies were performed on HEK-293 cells following methods described by Stamenić et al. [31] (online supplementary Methods). HEK-293 cells were transfected with cDNAs encoding rat GABAAR subunits. To determine the equilibrium binding 
constant $(\mathrm{KD})$ of $[3 \mathrm{H}]$-flunitrazepam for the various receptor subtypes, membranes were incubated with various concentrations of $[3 \mathrm{H}]$-flunitrazepam in the absence or presence of $5 \mathrm{mM}$ DZP. Drug concentrations resulting in half maximal inhibition of specific $[3 \mathrm{H}]$-flunitrazepam binding (IC50) were converted to Ki values by using the Cheng-Prusoff relationship.

\section{Animals}

Young (2-3 months) or old (21-22 months) C57BL/6 mice were obtained from Jackson Laboratories (US) or the Military Medical Academy (Serbia) and kept in normal housing conditions with a 12-hour light-dark cycle and water and food ad libitum. Animals were group-housed when not subjected to chronic stress (CS) and single-housed during the CS protocol. Old mice were obtained as retired breeders and were kept single-housed to prevent agonistic aggression between individuals. Testing took place during the light phase and was conducted in accordance with the Canadian or US institutional animal care committee and the Ethical Commission on Animal Experimentation of the Faculty of Pharmacy in Belgrade (carried out in accordance with the EEC Directive 86/609; see online supplementary material for details).

\section{Chronic Stress}

To induce a cognitive deficit in young mice, animals were subjected to a CS protocol. They were placed twice a day for $1 \mathrm{~h}$ in a 50 -mL Falcon ${ }^{\circledR}$ tube perforated on each end to allow air circulation. CS was applied for at least 10 days before testing but was not applied on testing days.

\section{Ligand Preparation and Administration}

Ligands were diluted in a vehicle solution containing $85 \%$ distilled $\mathrm{H}_{2} \mathrm{O}, 14 \%$ propylene glycol, and $1 \%$ Tween- 80 and administered intraperitoneally (i.p.) at a volume of $10 \mathrm{~mL} / \mathrm{kg}$. Working solutions were prepared at 1,5 , or $10 \mathrm{mg} / \mathrm{kg}$ and adjusted to body weight before injection. DZP was used as a non-selective GABAAR PAM and was administered i.p. at $1.5 \mathrm{mg} / \mathrm{kg}$.

For subchronic administration, ligands were diluted in tap water, stirred overnight at room temperature, and provided in glass bottles to tailor for a $30 \mathrm{mg} / \mathrm{kg}$ daily dose for 10 consecutive days. The dose of $30 \mathrm{mg} / \mathrm{kg}$ daily was used to approximatively match the brain concentration of ligand found after $10 \mathrm{mg} / \mathrm{kg}$ i.p. injection. Bottles were changed every other day to provide freshly prepared solutions.

Fig. 1. Electrophysiological recordings at GABA-A receptors. Modulation properties of $100 \mathrm{nM}$ or $1 \mu \mathrm{M}$ of GL-II-73 (a, e), GLII-74 (b, f), GL-II-75 (c, g), or GL-II-76 (d, h) at recombinant $\alpha 1 / 2 / 3 / 4 / 5 / 6 \beta 3 \gamma 2(\mathbf{a}-\mathbf{d})$ or $\alpha 1 \beta 1 / 3 \gamma 2(\mathbf{e}-\mathbf{h})$ receptors. The potentiation of GABA alone ( $\left.\mathrm{EC}_{3-5} \mathrm{GABA}\right)$ is expressed in percentage. ${ }^{*} p<0.05,{ }^{* *} p<0.01$, and ${ }^{* * *} p<0.001$ compared to $100 \%{ }^{*}{ }^{+} p<$ 0.05 compared to $\alpha 5 \beta 3 \gamma 2$; $p<0.05$ compared to $\alpha 1 \beta 3 \gamma 2$. The approximated electrophysiological responses elicited by the estimated free brain concentrations and presented on the concentrationresponse curves of GL-II-73 (i), GL-II-74 (j), GL-II-75 (k), and

\section{Pharmacokinetic Characterization}

Metabolism studies were performed in human and mouse liver microsomes as described by Namjoshi et al. [35]. The ligands were incubated at $10 \mu \mathrm{M}$ with active or heat-inactivated human or mouse liver microsomes and appropriate cofactors. Aliquots were removed at different time points and assayed using liquid chromatography/tandem mass spectrometry (LC-MS/MS). To obtain pharmacokinetic profiles, mice were treated i.p. at $10 \mathrm{mg} / \mathrm{kg}$ and sacrificed at different time points ( 5 to 720 min post-injection) for brain and plasma quantification of ligands by ultraperformance LC-MS/MS [36]. The analytical lower limit of quantification for the ligands examined ranged from 0.5 to $1.0 \mathrm{ng} / \mathrm{mL}$ in plasma, and from 0.2 to $1.0 \mathrm{ng} / \mathrm{g}$ in brain tissue.

\section{In vitro Hydrolytic Plasma Stability Studies}

The ligands' stabilities were tested in vitro at $37^{\circ} \mathrm{C}$, utilizing blank mouse plasma spiked with individual ligand and internal standard, as described by Stamenić et al. [31].

\section{Plasma Protein and Brain Tissue Binding Studies}

A rapid equilibrium dialysis assay was used to determine the free fraction of the ligands in mouse plasma and brain tissue as described by Obradović et al. [36]. Ligand-free brain concentrations were calculated by multiplying the total brain concentrations with the appropriate free fractions determined by rapid equilibrium dialysis.

\section{Behavioral Assessment}

The ligands and DZP were tested in behavioral tests assessing anxiety-like behavior (elevated plus maze, EPM), antidepressant predictability (forced swim test, FST), locomotor activity (Open Field), and spatial working memory (Y-maze, YM). To assess anxiety-like behaviors, mice were tested in the EPM for $10 \mathrm{~min}$, in bright light condition (100 lux). Animals were injected i.p. with the test ligand, the control substance DZP, or vehicle solution $30 \mathrm{~min}$ prior testing. Increased time spent in the open arms was considered an index for potential anxiolytic effect of the ligands. In order to determine potential antidepressant properties of the ligands, mice were tested in the FST for 6 min. Following classical guidelines to test antidepressant in mice, animals received 3 injections 24,20 , and $1 \mathrm{~h}$ prior to testing. Increase in mobility was quantified as a proxy for potential antidepressant property of the ligand. In order to determine the effect of the ligands on reversing stressinduced or age-related cognitive deficits, mice were tested in an alternation task in the YM. Alternation rate in this task was used as a proxy of working memory performances. Detailed methods

$\mathrm{DZP}(\mathrm{I})$ at rat recombinant $\alpha 1 \beta 3 \gamma 2$ and $\alpha 5 \beta 3 \gamma 2 \mathrm{GABA}-\mathrm{A}$ receptors measured at $\mathrm{GABA} \mathrm{EC}_{3}$ (eliciting $3 \%$ of the maximal GABA current in the respective subtype). Brain tissue density of $1.04 \mathrm{~g} / \mathrm{mL}$ was used to convert brain concentrations from $\mathrm{ng} / \mathrm{g}$ into $\mathrm{ng} / \mathrm{mL}$. The shaded range delineates the interpolated lower and upper limit of potentiation at a5-GABA-A receptors in the dose range used; the vertical lines mark the approximated free brain concentration of the given dose of each ligand. The level of potentiation of $120 \%$ was arbitrarily set as borderline for eliciting in vivo behavioral effects.

(For figure see next page.)
Prevot et al. 


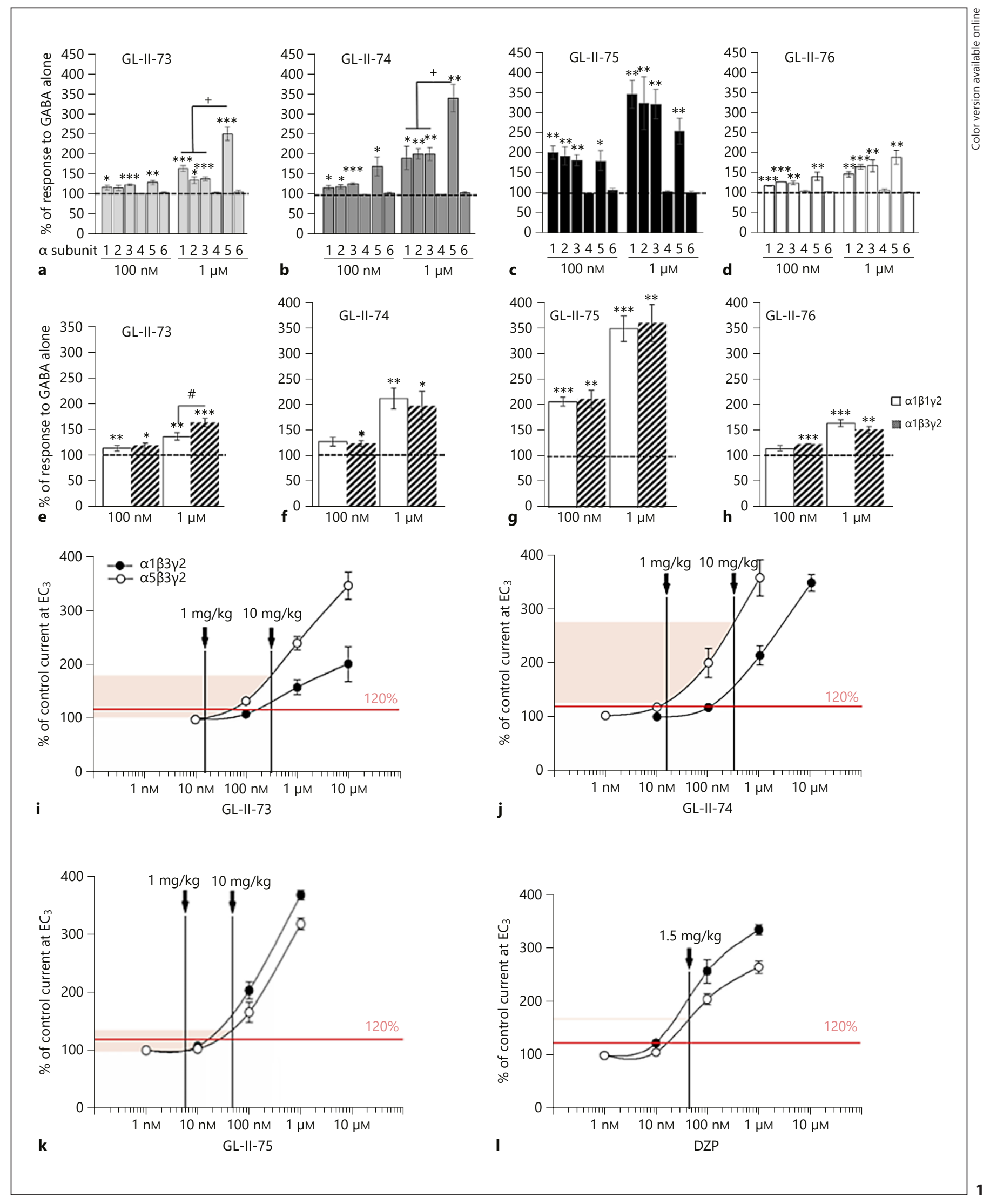

Novel Benzodiazepine-Like Ligands with 
were described by Vandesquille et al. [30] and more information is available in the online supplementary Methods.

\section{Statistical Analysis}

All data are expressed as mean \pm SEM. Data obtained from electrophysiology studies were subjected to $t$ tests comparing the mean response to $100 \%$ of response to GABA alone. For behavioral experiments, statistical analyses were performed using one-way ANOVA and post hoc Scheffe's or Student-Newman-Keuls test when applicable. For the EPM and YM tests, sex was put as a cofactor to investigate potential sex effects on the behavioral outcome. All values obtained after statistical analysis are provided in the online supplementary Tables S1-S3 and S8-S11.

\section{Results}

\section{Potentiation at $\alpha$-Containing GABAA-Rs}

The effects of four new IBZD amide ligands were compared to the response to GABA alone $\left(\mathrm{EC}_{3-5}\right)$ at the different $a$-containing recombinant GABAA-Rs (Fig. 1a-d and online suppl. Table S1). At $100 \mathrm{nM}, \mathrm{GL}-\mathrm{II}-74$ and GLII-75 exhibited substantial allosteric modulation at a5GABAA-Rs, while GL-II-73 and GL-II-76 exhibited lower and significant potentiation ( $t$ test comparison to $100 \% ; t>2.9 ; p<0.04)$. At this low concentration, all ligands also potentiate $\alpha 1, \alpha 2$, and $\alpha 3$-GABAA-Rs $(t>2.9$; $p<0.04)$. GL-II-75 exhibited high potentiation at all four subunits, suggesting shared electrophysiological properties with the non-selective PAM DZP. Indeed, at the same concentration (100 nM), DZP induces a slightly more robust potentiation at $\alpha 1, \alpha 2, \alpha 3$, and $\alpha 5$-containing GABAA receptors of the magnitude $>200 \%$ [37]. The profiles at $100 \mathrm{nM}$ were confirmed at $1 \mu \mathrm{M}$ concentration, with strong a5-PAM effects ( $t$ test comparison to $100 \%$; $t>4.67 ; p<0.009$ ) and lower potentiation at $\alpha 1, \alpha 2$, and $\alpha 3$ for GL-II-73 and GL-II-74 $(t>3.17$; $p<0.03)$. ANOVA comparing potentiation at $1 \mu \mathrm{M}$ across subunits confirmed that GL-II-73 and GL-II-74, but not GL-II-75, preferentially potentiate a5-GABAA-Rs ( $p<0.04$; online suppl. Table S2). As expected, $a 4-, a 6-$, or $\delta$-subunitcontaining GABAA-Rs were not potentiated by the new ligands (online suppl. Table S1) suggesting mediation by the BZD site and similar subunit-dependent activity as DZP [38]. Similar potentiation levels were obtained at the $\beta 1$ - and $\beta 3$-containing GABAA-Rs (besides a significant difference for GL-II-73 at $1 \mu \mathrm{M}$ concentration [ $p=0.03]$, but irrelevant for in vivo application) suggesting no critical impact of the $\beta$ subunit on the modulatory effects of the new ligands (Fig. 1e-h and online suppl. Table S3).

\section{Ligand Selection and Dose Validation for Animal \\ Studies}

Liver microsome metabolism assays (online suppl. Table S4) indicated that GL-II-73 and GL-II-74 had the longest half-lives in mouse and human, respectively, while GL-II-76 had a very short half-life in mice, precluding its use in vivo; hence, it was excluded from further analysis.

Considering the implication of a1-GABAA-Rs in sedation, we aimed at finding a dose that would have limited potentiation at $\alpha 1-$ GABAA-Rs but that would potentiate a5-GABAA-Rs. The concentration-response curves for the ligands (Fig. 1i-k and online suppl. Table S5) suggest that at $1 \mathrm{mg} / \mathrm{kg}$, the expected potentiation would be below $120 \%$ for GL-II-73 and GL-II-75 at both a1- and a5-GABAA-Rs, while GL-II-74 would have significant potentiation at a5-GABAA-Rs. At $10 \mathrm{mg} / \mathrm{kg}$, potentiation would significantly increase for both subunits, with higher potentiation at a5- than a1-GABAA-Rs for GLII-73 and GL-II-74. Conversely, GL-II-75 exhibited higher potentiation at $\alpha 1$ - than at $\alpha 5-G A B A A-R s$ at $10 \mathrm{mg} / \mathrm{kg}$, similar to the non-selective reference compound DZP (Fig. 11). Nevertheless, due to a low free fraction of GLII-75 in brain tissue, the magnitude of potentiation at a 1 GABAA-Rs by GL-II-75 at $10 \mathrm{mg} / \mathrm{kg}$ (Fig. 1k) is estimated to be substantially below the potentiation induced by DZP $1.5 \mathrm{mg} / \mathrm{kg}$, and in fact close to that estimated for GL-II-73 and GL-II-74 at $10 \mathrm{mg} / \mathrm{kg}$ (online suppl. Table S7).

Potentiation of GABA-induced chloride current does not necessarily correlate with binding affinity. Indeed, binding assays at $\alpha 1 / 2 / 3 / 5$-GABAA-Rs showed that all ligands are affinity-selective to the a5-GABAA-R (Ki values being 6-15 times more potent at a5-GABAA-R than
Fig. 2. Plasma and brain concentration-time profiles of GL-II-73 (a), GL-II-74 (b), GL-II-75 (c), and DZP (d) after intraperitoneal administration of the $10 \mathrm{mg} / \mathrm{kg}$ dose in male C57BL/6 mice $(n=$ 3 per time point). $\mathrm{C}_{\max }$, maximum concentration in plasma or brain; $\mathrm{T}_{\max }$, time of maximum concentration in plasma or brain; $\mathrm{AUC}_{0-720}$, area under the plasma or brain concentration-time curve from 0 to $720 \mathrm{~min}$; $\mathrm{AUC}_{0-\infty}$, area under the plasma or brain concentration-time curve from 0 to extrapolated infinite time; $\mathrm{T}^{1} / 2$, elimination half-life from plasma or brain; $\beta$, elimination constant rate from plasma or brain; $\mathrm{K}_{\mathrm{p}}$, brain-to-plasma partition coefficient $\left(\mathrm{K}_{\mathrm{p}}=\mathrm{AUC}_{0-\infty}\right.$, brain/ $\mathrm{AUC}_{0-\infty}$, plasma); $\mathrm{K}_{\mathrm{p} \text {,uu }}$, ratio of unbound brain to unbound plasma drug concentrations $\left(K_{p, u u}=K_{p}\right.$ $\times$ unbound fraction in brain/unbound fraction in plasma). All values are represented as mean \pm standard error of the mean.

(For figure see next page.)
88

Mol Neuropsychiatry 2019;5:84-97 DOI: $10.1159 / 000496086$
Prevot et al. 


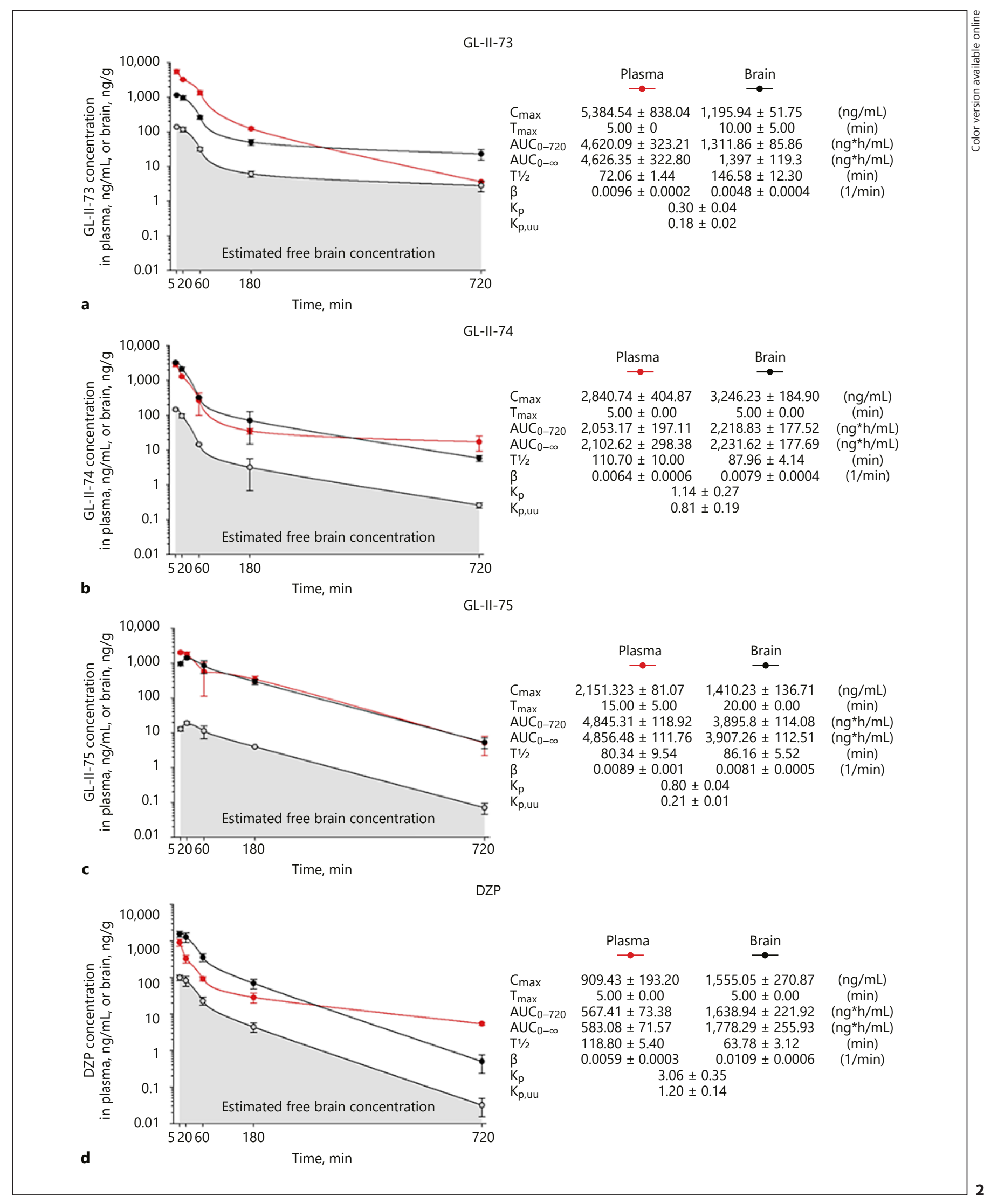

Novel Benzodiazepine-Like Ligands with 
other a-GABAA-Rs; online suppl. Table S6). Notably, GL-II-73 showed the lowest affinities, with Ki values in the low $\mu \mathrm{M}$ range, compared to the other ligands. In contrast to all four novel ligands, DZP demonstrated high and similar affinities at all $\alpha-$ GABAA-Rs.

\section{Pharmacokinetic Profiles, Plasma Stability, and Free}

Fraction Studies

Pharmacokinetic profiles of the test ligands and DZP were established in mice after $10 \mathrm{mg} / \mathrm{kg}$ i.p. administration (Fig. 2a-d). Plasma and brain free fractions were 20.39 and $12.14 \%$ for GL-II-73, 6.34 and $4.49 \%$ for GLII-74, 5.08 and $1.34 \%$ for GL-II-75, and 16.25 and $6.38 \%$ for DZP, respectively. Elimination half-lives of all three ligands and DZP suggest that DZP and GL-II-74 are the most stable in mouse plasma, while GL-II-73 is most stable in the mouse brain.

Maximum brain concentration was the highest with GL-II-74, suggesting a relatively optimized capacity for brain targeting. Examination of brain-to-plasma partition coefficient $\left(\mathrm{K}_{\mathrm{p}}\right)$ values showed that GL-II-74 displayed excellent brain permeability, although less efficient than DZP $\left(K_{p}=1.14\right.$ vs. 3.06). This was further supported by the ratio of unbound brain to unbound plasma ligand concentrations values $\left(\mathrm{K}_{\mathrm{p} \text {,uu }}\right)$, a measure of net transport across the blood-brain barrier, which better quantifies the brain penetration efficiency [39]. This parameter demonstrated that GL-II-73 may be a substrate for efflux transport mechanisms at the blood-brain barrier, compared to GL-II-74 or GL-II-75. Although DZP displayed excellent brain permeability (as measured by $\mathrm{K}_{\mathrm{p}}$ and $\mathrm{K}_{\mathrm{p}, \mathrm{uu}}$ ), GL-II-74 and GL-II-75 reached notably higher AUC brain values than DZP. The brain AUC value for GL-II-73 was somewhat lower but comparable to DZP.

All three ligands displayed acceptable brain penetration and an excellent in vitro metabolic stability; after $4 \mathrm{~h}$ of incubation in mouse plasma, the fraction of remaining intact ligand was $98.88,85.83$, and $78.52 \%$ for GL-II-73, GL-II-74, and GL-II-75, respectively, whereas the intact fraction of DZP was only $76.36 \%$. Thus, the novel ligands have at least as favorable pharmacokinetic properties as DZP.

The concentrations of all ligands in mouse brain 30 min after single or $1 \mathrm{~h}$ after the last of three i.p. injections (administered 24, 20, and $1 \mathrm{~h}$ prior to determination of concentration) at 1,5 , and $10 \mathrm{mg} / \mathrm{kg}$ (online suppl. Fig. S2 and Table S7) demonstrated that attainable concentrations were governed by the dose and dosage regimen. In view of the potentiation at $\alpha 1$ - and $\alpha 5$-GABAA-Rs (Fig. 1) and pharmacokinetic properties (Fig. 2), doses of 1, 5, and $10 \mathrm{mg} / \mathrm{kg}$ were chosen for behavioral testing.

\section{Anxiolytic and Antidepressant-Predictive Properties}

In the EPM test, GL-II-73 and GL-II-74 demonstrated significantly increased percentage of time spent in the open arms (ANOVA $F>3.7 ; p<0.03$ ), while GL-II-75 did not reach significance $(p=0.07)$. Post hoc analysis identified a significant increase in time after i.p. administration at $10 \mathrm{mg} / \mathrm{kg}(p<0.03)$ for GL-II-73 and GL-II-74 (Fig. 3a, $\mathrm{b}$ and online suppl. Table S8). $1.5 \mathrm{mg} / \mathrm{kg}$ DZP significantly increased the time spent in the open arms $(p=0.02)$, confirming its known anxiolytic property.

In the FST, GL-II-73, GL-II-74, and GL-II-75 induced significant decreases in time spent immobile (ANOVAs $F>5.4 ; p<0.004)$ compared to vehicle-injected groups at $10 \mathrm{mg} / \mathrm{kg}(p<0.003$; Fig. 3e-h). Reduced immobility was also found at $5 \mathrm{mg} / \mathrm{kg}$ for GL-II-74 and GL-II-75 $(p<$ $0.03)$. In contrast, DZP significantly increased time spent immobile $(p=0.004)$, potentially due to locomotor side effects (online suppl. Fig. S3), thus precluding any conclusion as to putative depressant-like effect. Locomotor activity assessment indicated no change for all ligands at the dose and time frame of the FST test (i.e., $60 \mathrm{~min}$; online suppl. Fig. S4).

\section{Reversal of Stress-Induced Working Memory Deficit}

Adult mice were exposed to CS to induce working memory impairments in a YM spontaneous alternation task and injected with ligands or vehicle. ANOVAs revealed differences in alternation rate after CS exposure and ligand injection $(F>7 ; p<0.0004)$. CS exposure decreased alternation rates in animals receiving vehicle $(p<$ 0.002; Fig. 4a-d and online suppl. Table S9). Administration of GL-II-73 at $10 \mathrm{mg} / \mathrm{kg}$ restored alternation rate in CS animals to the same level as non-CS animals, and they were significantly different from the CS mice receiving vehicle $(p=0.01)$. The $1-$ and $5-\mathrm{mg} / \mathrm{kg}$ doses of GL-II-73 had no effect. In contrast, CS animals injected with GLII-74 displayed lower alternation rate than non-CS animals, demonstrating no effect on working memory at the tested doses $(p>0.97)$. GL-II-75 administration restored alternation rate to non-CS levels at 5 and $10 \mathrm{mg} / \mathrm{kg}(p<$ 0.045 ). As expected, administration of $1.5 \mathrm{mg} / \mathrm{kg}$ of DZP did not reverse the cognitive deficits induced by CS ( $p=$ $0.94)$.

We also tested the ligands in non-CS animals to assess putative effects at baseline (online suppl. Fig. S5 and Table S9). GL-II-73 and GL-II-75 had no effect on alternation rates (ANOVAs $F<2.4, p>0.3$ ), whereas $10 \mathrm{mg} / \mathrm{kg}$
Prevot et al. 


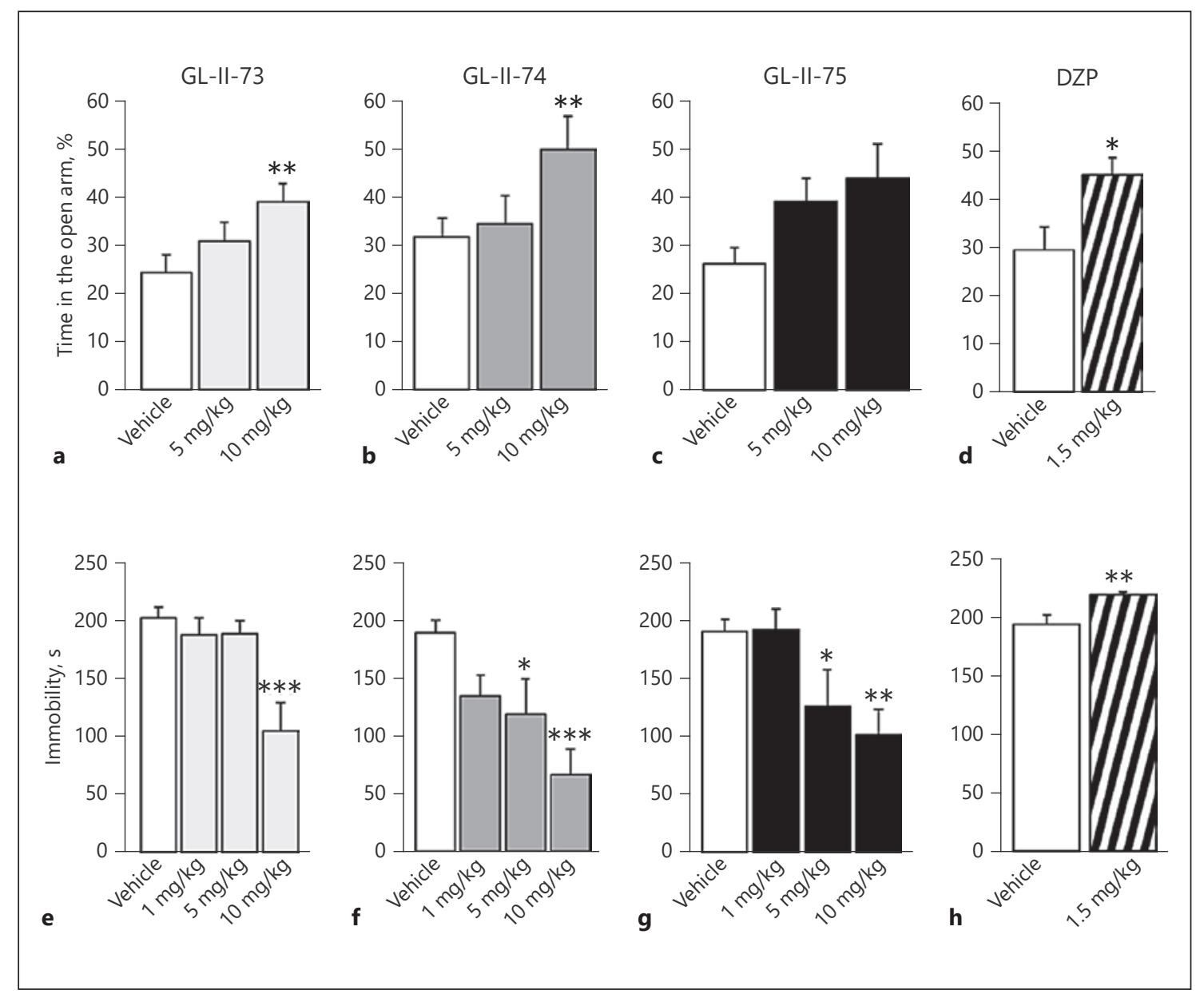

Fig. 3. Anxiolytic and antidepressant properties of novel ligands compared to diazepam (DZP). Potential anxiolytic action of the new IBZD amide ligands GL-II-73 (a), GL-II-74 (b), and GL-II-75 (c) at 5 or $10 \mathrm{mg} / \mathrm{kg}$ and the reference non-selective GABA-A receptor PAM DZP $(1.5 \mathrm{mg} / \mathrm{kg}$; d) was assessed in mice $(50 \% \mathrm{fe}-$ males) using the elevated plus maze. Animals received vehicle or the ligand GL-II-73 $(n(0)=13, n(5)=13$, and $n(10)=14)$, GL-II-74 $(n(0)=14, n(5)=13$, and $n(10)=14)$, GL-II-75 $(n(0)=13, n(5)=$ 14 , and $n(10)=13)$, or DZP $(n(0)=11$ and $n(1.5)=10) 30 \mathrm{~min}$ before testing. A significant increase in the time spent in the open arms was used as an index of potential anxiolytic action. Sex as a cofactor was not significant ( $p$ values $\geq 0.17$ ). Potential antidepressant properties of the ligands were assessed in male mice using the

of GL-II-74 and $1.5 \mathrm{mg} / \mathrm{kg}$ of DZP reduced alternation rates (ANOVAs $F>8.8 ; p<0.005$ ), suggesting deleterious effects on working memory.

\section{Reversal of Age-Induced Working Memory Deficit}

The efficacies of GL-II-73 and GL-II-75 in reversing working memory deficits were next assessed in old male mice. ANOVAs revealed significant differences between forced swim test (e-h). Mice were placed in an inescapable transparent tank filled with water $\left(25 \mathrm{~cm}, 26 \pm 1{ }^{\circ} \mathrm{C}\right)$ for a period of 6 min. Immobility is defined as the minimum amount of movement to stay afloat, between the second and the sixth minute of testing. Mice were injected following serial i.p. administrations at 1,5, or $10 \mathrm{mg} / \mathrm{kg}$ for the new ligands (GL-II-73: $n(0)=8, n(1)=8, n(5)=$ 6 , and $n(10)=8$; GL-II-74: $n(0)=8, n(1)=8, n(5)=8$, and $n(10)=8$; GL-II-75: $n(0)=8, n(1)=8, n(5)=8$, and $n(10)=9$ ) or $1.5 \mathrm{mg} / \mathrm{kg}$ for the DZP $(n(0)=12$ and $n(1.5)=12)$. Significant decreased immobility characterized the potential antidepressant-like efficacy of the ligand. ${ }^{*} p<0.05,{ }^{* *} p<0.01$, and ${ }^{* * *} p<0.001 \mathrm{com}$ pared to vehicle. All values are represented as mean \pm standard error of the mean. YM at chance level, suggesting cognitive impairment $(p<$ 0.002 compared to young mice). At $5 \mathrm{mg} / \mathrm{kg}$, GL-II-73 or GL-II-75 significantly reversed spatial working memory deficits of old mice to levels indistinguishable from young controls $(p<0.03$ compared to old vehicle; Fig. $4 \mathrm{e}-\mathrm{f}$ and online suppl. Table S10). 
GL-II-73

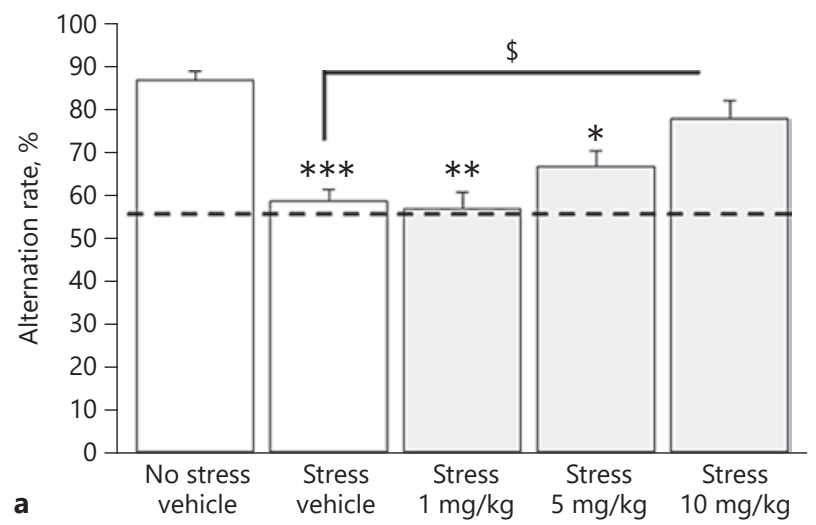

GL-II-75

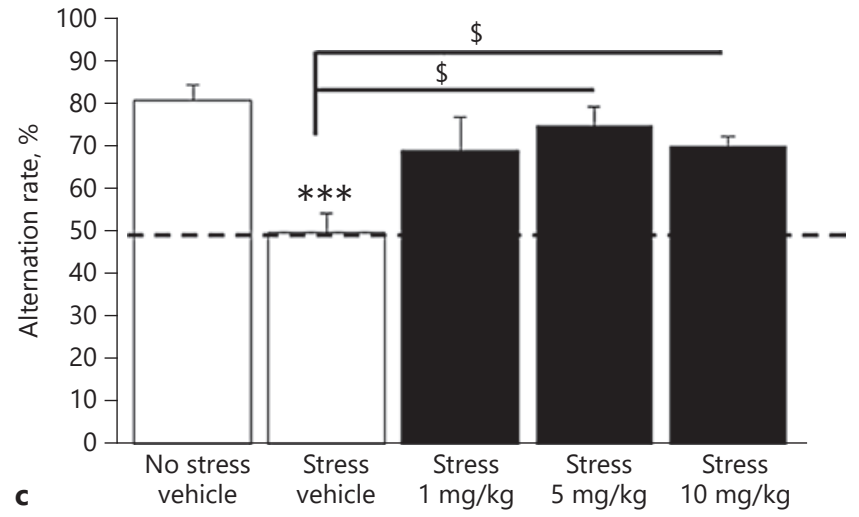

GL-II-74

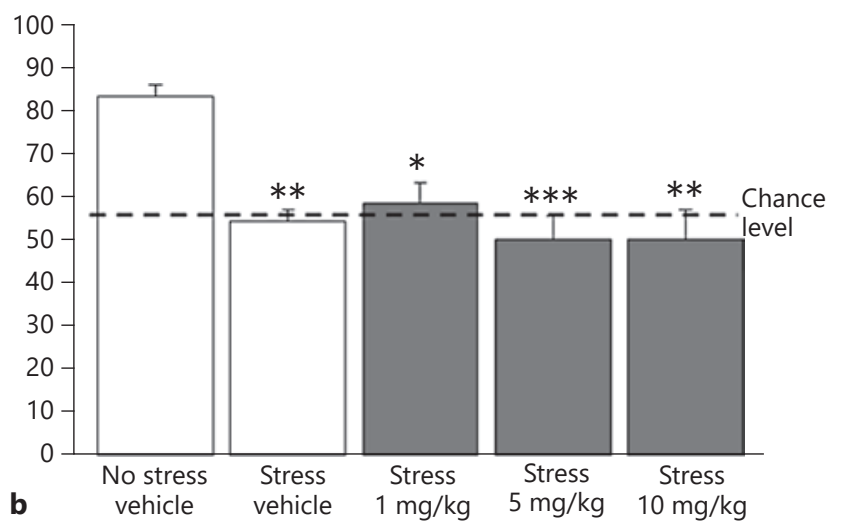

DZP

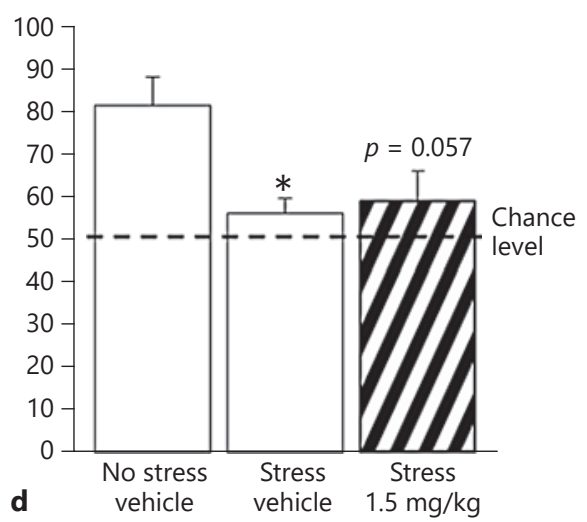

GL-II-73

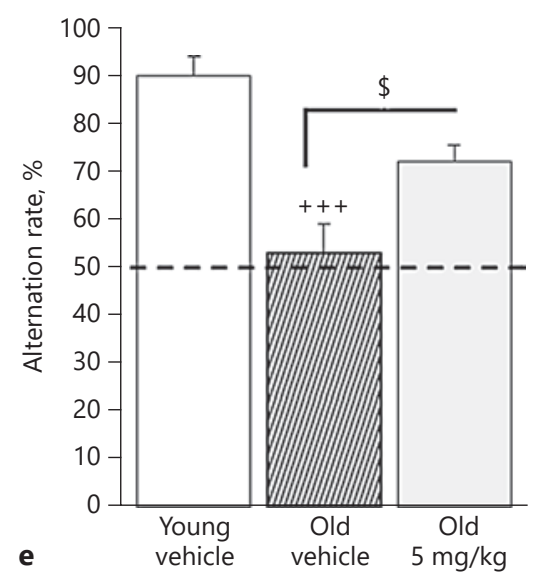

GL-II-75

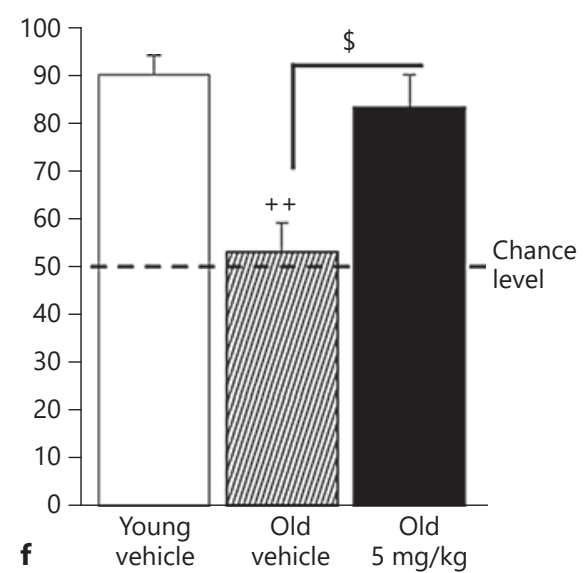

4

(For legend see next page.) 


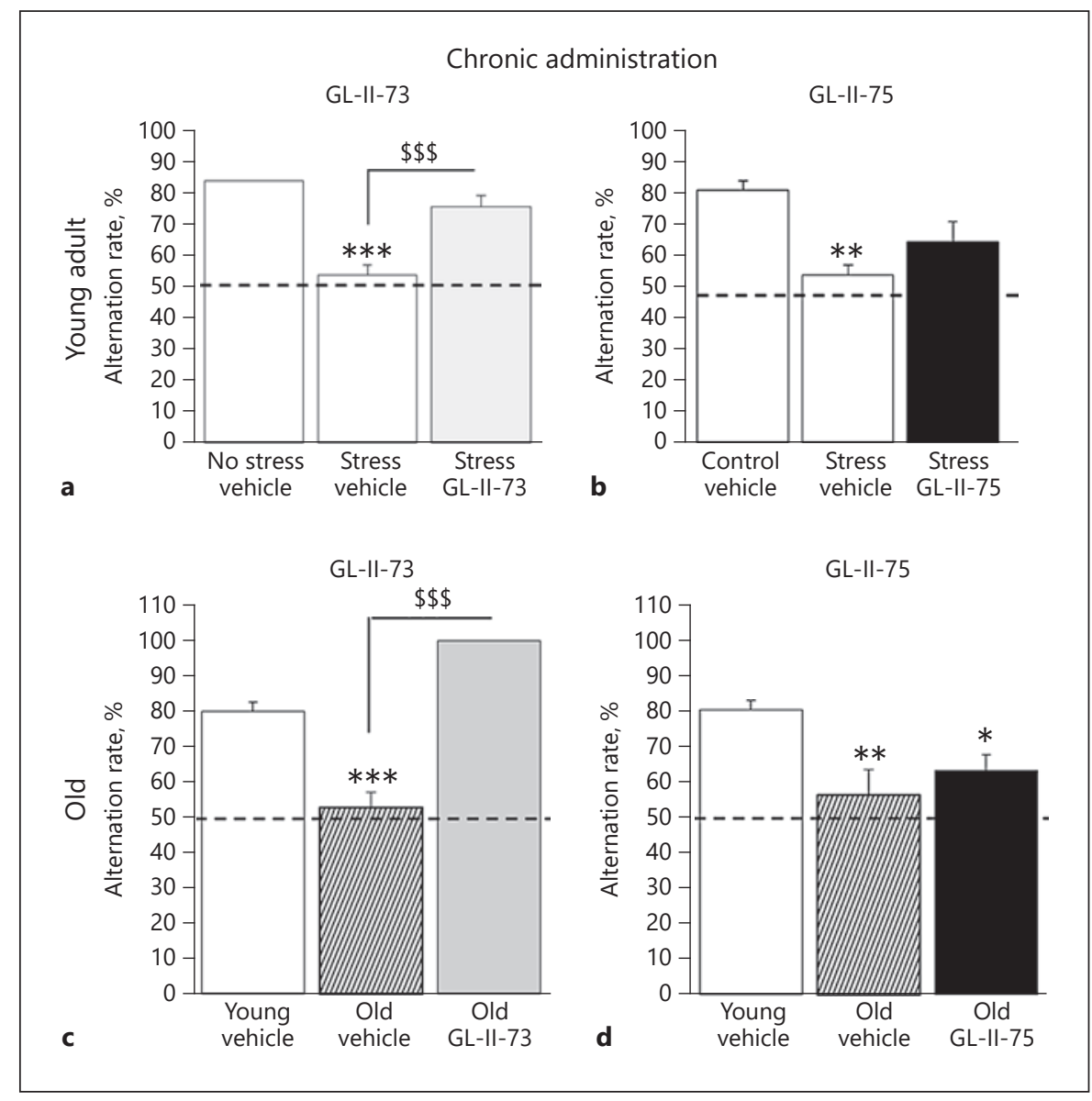

Fig. 5. Pro-cognitive efficacy of subchronically administered GLII-73 and GL-II-75 on stress-induced and age-related working memory impairment. Effects on working memory of GL-II-73 (a, c) and GL-II-75 (b, d) were assessed in young $(\mathbf{a}, \mathbf{b})$ and old $(\mathbf{c}, \mathbf{d})$ male mice after subchronic administration in the drinking water for 10 days, using a spontaneous alternation task. Alternation rate was calculated as the percentage of correct alternations in function of the maximum alternation possible (i.e., 6). Prior to experiment, a cognitive deficit was induced by exposing the young animals to chronic stress for 1 week. Young animals received subchron- ically GL-II-73 $(n(0-\mathrm{NS})=6, n(0-\mathrm{S})=5, n(30)=6)$ or GL-II-75 $(n(0-\mathrm{NS})=5, n(0-\mathrm{S})=5, n(30)=6)$ dosed at $30 \mathrm{mg} / \mathrm{kg}$. Old mice received subchronically GL-II-73 $(n(0$-Young $)=5, n(0$-Old $)=6$, $n(30)=4)$ or GL-II-75 $(n(0$-Young $)=6, n(0-$ Old $)=5, n(30)=5)$ dosed at $30 \mathrm{mg} / \mathrm{kg}$ in the drinking water. Results are presented as mean of the percentage of alternation \pm SEM. Effect of the stress: ${ }^{*} p<0.05,{ }^{* *} p<0.01$, and ${ }^{* * *} p<0.001$ compared to "No stress vehicle." Effect of the ligand: ${ }^{\$ \$} p<0.001$ compared to "Stress vehicle" or "Old vehicle."
Fig. 4. Pro-cognitive efficacy of GL-II-73 and GL-II-75 on stressinduced and age-related working memory impairment. Effects on working memory were assessed in a spontaneous alternation task using a 90-second inter-trial interval. Prior to the experiment with young mice, a cognitive deficit was induced by exposing the animals to daily chronic restraint stress, $1 \mathrm{~h}$ twice a day for 1 week. Young mice (50\% females) received vehicle or 1,5 , or $10 \mathrm{mg} / \mathrm{kg}$ of GL-II-73 (a; $n(0-\mathrm{NS})=10, n(0-\mathrm{S})=10, n(1)=5, n(5)=10$, $n(10)=12)$. The same protocol was used for GL-II-74 (b; $n(0-\mathrm{NS})=8, n(0-\mathrm{S})=8, n(1)=4, n(5)=10, n(10)=4)$, GL-II-75 (c; $n(0-\mathrm{NS})=8, n(0-\mathrm{S})=8, n(1)=6, n(5)=4, n(10)=9)$, and DZP (d; $n(0-\mathrm{NS})=6, n(0-\mathrm{S})=6, n(1.5)=6$ ). Animals were injected i.p. with vehicle, a5-PAMs, or DZP, 30 min prior testing. For old animals $(\mathbf{e}, \mathbf{f})$, the same protocol was applied with the inter-trial interval shortened to $60 \mathrm{~s}$. Old male mice received vehicle or GLII-73 (e; $n(0$-Young $)=5, n(0$-Old $)=5, n(5)=6)$ or GL-II-75 (f; $n(0$-Young $)=5, n(0$-Old $)=5, n(5)=4)$ and were compared to young and old mice treated with vehicle. For all experiments described here, sex as a cofactor was not significant ( $p$ value $\geq 0.49$ ). Results are presented as mean of the percentage of alternation \pm SEM. Effect of the stress: ${ }^{*} p<0.05,{ }^{* *} p<0.01,{ }^{* * *} p<0.001 \mathrm{com}-$ pared to "No stress vehicle." Effect of age: ${ }^{++} p<0.01$ or ${ }^{+++} p<$ 0.001 compared to "Young vehicle." Effect of the ligand: ${ }^{\$} p<0.05$ compared to "Stress vehicle" or "Old vehicle." 
Subchronic Administration in Young and Old Mice

The two ligands that reversed working memory deficits after a single acute i.p. injection (GL-II-73 and GLII-75) were tested via subchronic administration (10 days in drinking water) (Fig. 5 and online suppl. Table S11). In the CS-induced working memory deficit model, ANOVA revealed significant differences between groups only with GL-II-73 injection $(F(2,14)=28.1 ; p=0.0001)$, characterized by increased alternation rate after subchronic administration ( $p=0.005$ compared to CS mice). A similar result was obtained in the age-induced working memory deficit model, where GL-II-73 ( $p=0.0001$ ), but not GLII-75 ( $p=0.46)$, increased alternation rate after subchronic administration.

\section{Discussion}

This work was based on the hypotheses that deficits in GABA signaling contribute to mood and cognitive symptoms in depression and aging, and that enhancement of activity at GABAA-Rs, but with limited action at a1GABAA-R, may have therapeutic potential for these symptom dimensions, compared to highly potent BZs that lack such activities. Three of the four newly synthetized IBZDlike compounds displayed adequate brain penetration and were further investigated. Using validated screening tests, we showed that the ligands display unique therapeutic profiles, including anxiolytic- and antidepressant-predictive properties, and pro-cognitive properties in GL-II-73, reversing stress-induced and age-related working memory deficits. The three novel ligands displayed reduced side effects compared to DZP (such as sedation and amnesia), consistent with reduced $\alpha 1$ potentiation [40-42].

Binding and electrophysiological studies indicated that GL-II-73 and GL-II-74 acted as PAMs with priority affinity and efficacy at a5-GABAA-Rs, whereas GL-II-75 potentiated GABA-gated chloride current to a greater extent at $\alpha 1-, \alpha 2-$, and $\alpha 3-G A B A A-R s$ compared to a5GABAA-R, suggesting properties closer to DZP [37], although with much lower overall affinity than DZP. The lack of potentiation at GABAA-Rs containing the $a 4, a 6$, or $\delta$ subunits supports the notion that all ligands bind to the DZP-specific BZ-sensitive site of GABAA-Rs [12].

Brain and plasma pharmacokinetic studies showed that all ligands are brain-penetrant, with indices ranked in the following decreasing order: DZP $>$ GL-II-74 > GLII-75 > GL-II-73. Accordingly, all ligands were tested for behavioral activity in vivo. Two of the three ligands and DZP demonstrated similar anxiolytic properties despite variable efficacy profiles (the third ligand, GL-II-75, being not significant but showing a strong trend: $p=0.07$ ). Note that these effects could be partially mediated by additional modulatory activity at $\alpha 2-$ GABAA-Rs [16]. The fact that GL-II-75 did not show a significant increase in the time spent in the open arm may relate to its potential effect at reducing locomotor activity $30 \mathrm{~min}$ after administration (online suppl Fig. 4). Even though no effects were observed in the locomotor activity in the EPM (not shown), the effects observed in the OF suggest that reduced activity at this time point might be confounding with the potential anxiolytic effects of the ligand.

All three ligands displayed antidepressant-predictive properties, at doses and time points that induced no locomotor effect. Indeed, locomotor activity assessment in the Open Field showed no effect of any ligand $1 \mathrm{~h}$ after the administration. However, GL-II-75 showed significant decrease in locomotor activity up to $40 \mathrm{~min}$ after administration. This extinction of locomotor impairment might result from the decreasing concentration of the ligand in the brain over time, leading to reduced $\alpha 1$ potentiation and reduced side effects on locomotion, as this particular compound displays high potency at a1GABAA-R. For comparison, GL-II-73 affinity for a1GABAA-Rs is exceptionally low, profoundly decreasing the propensity to elicit motor impairment. In contrast, DZP increased the time spent immobile, confirming its lack of antidepressant effect, or suggesting it induces a depressant-like state $[43,44]$, although this was probably confounded by motor-impairing effects. Clearly, all three ligands differ from DZP, although the extent of these putative antidepressant effects will need to be confirmed using CS or genetic rodent models.

Two of the three novel ligands (GL-II-73 and GLII-75) reversed spatial working memory deficits induced by CS exposure [45], while DZP did not restore such deficits and even induced cognitive impairment at baseline, consistent with previous findings [46]. These effects were confirmed in independent cohorts of mice with normal age-related cognitive deficits. Notably, GL-II-73 but not GL-II-75 effects were maintained after subchronic administration in both models. It remains to be tested whether this difference reflected the diverse kinetic parameters of GL-II-75 and/or potential receptor desensitization. Together, these results demonstrate for the first time the potential for anxiolytic, antidepressant, and procognitive properties of IBZD derivatives with reduced, but not abolished efficacy at a1-GABAA-Rs.

Interestingly, other studies have demonstrated that BZ derivatives, acting as selective a5-PAM, restore age-relat-
Prevot et al. 
ed cognitive deficits in old rats [21], shining lights on the important role of a5-GABAA-Rs on cognitive processes. However, our results also echo recent findings that suggest the importance of the contribution of activity at other subunits as a critical factor for cognitive efficacy of GABAA-R signaling potentiation. Indeed, co-localization of the $\alpha 1, \alpha 5$, and $\gamma 2$ subunit in the hippocampus has been proposed as a necessary combination for successful spatial learning [15], although robust $\alpha 1-$ GABAA-R activation is thought to mediate the DZP-induced deleterious effects on learning and memory. Interestingly DZP-induced incapacitation can be reversed by blockade of a1GABAA-R activation or worsened by a5-GABAA-R blockade [42]. This suggests that proper cognitive functions require $\alpha 5$ potentiation and reduced, but present, $\alpha 1$ potentiation. Such a mechanism may explain the effects on working memory observed with GL-II-73 and GLII-75 in our studies, and also explain the lack of effect of compounds with greater selectivity for a5-GABAA-R but no potentiation at a1-GABAA-R, such as SH-053-2'F-R$\mathrm{CH} 3$ or MP-III-022 [31] in the YM (data not shown). As to the lack of pro-cognitive effects of GL-II-74, it may be connected with its more pronounced (relative to GLII-73 and GL-II-75) potentiation at a5-GABAA-R (online suppl. Table S7), which may be high enough to cause deterioration of cognitive processing, generally ascribed in studies with knock-in mice to substantial potentiation at this receptor population [31]. Follow-up tests for additional cognitive parameters, such as executive functions, cognitive flexibility, or impulsivity need to be performed to come to a definitive conclusion regarding efficacy on broader cognitive functions of the novel ligands.

Could all these apparently disparate findings be reconciled in light of other parameters tested in this study? Although not measured directly, the pharmacokinetic and binding affinity results suggest moderate a5-GABAA-R and low a1-GABAA-R occupancies by the three new ligands compared to the known high affinity, efficacy, and occupancy of BZD. Furthermore, this activity and putative occupancy profiles would be predicted to give rise to an improved side effect profile, together unmasking antidepressant or pro-cognitive potential of DZP derivatives. Such a "low affinity - low adversity" paradigm was previously proposed in drug pharmacology, compared to highaffinity drugs [47]. In this case, properties such as high dissociation rates and transient interaction of weak-binding drug can be key elements for drug efficacy with a low side effect profile. Hence, the high fractional occupation may preclude antidepressant or pro-cognitive properties, consistent with the pro-depressant-like [43] and amnesic

Novel Benzodiazepine-Like Ligands with Various Profiles effect of DZP [48], and the role of the $\alpha 1$ and $\alpha 5$ subunit may follow a biphasic pattern, where low activation facilitates mood and cognitive processes, whereas high activation impairs these same functions [49].

It is interesting to note that negative allosteric modulators (NAMs) at GABAA-Rs can also exert antidepressant [50] and pro-cognitive activity in recognition learning [51] and spatial memory [52], although reducing a5GABAA-R function is predicted to worsen the pathologies. The putative pro-cognitive properties of both a5NAMs and $\alpha 5$-PAMs are not mutually incompatible. $\alpha 5$ NAM could be acutely efficient in certain cognitive tasks such as spatial reference [52] where disinhibition of pyramidal neurons may facilitate the acquisition of a mental spatial map. In contrast, an a5-PAM could be efficient in cognitive tasks (such as working memory) where increased inhibition of neuronal activity may reduce noise and interferences, and increase signal-to-noise ratio for incoming stimuli $[53,54]$, together strengthening the salient inputs that need to be kept for high-level performances [55]. This hypothesis on the roles of NAMs and PAMs will require further validation and side-by-side comparison in multiple cognitive tasks.

Given the increased rates of cognitive and mood impairments with psychiatric diseases and aging, it is imperative to develop new therapeutic strategies based on emerging knowledge of primary pathologies of the diseases and novel pharmacology concepts. Here, we designed, tested, and validated preclinical efficacies of novel IBZD amide ligands acting as DZP derivatives with a low side effect profile. The fact that these ligands (1) are synthetized from the hybrid DZP/flumazenil privileged structure which usually exhibit very low toxicity profiles, (2) have moderate activity limiting potential side effects, and (3) exhibit combined antidepressant and pro-cognitive therapeutic potential (for GL-II-73 and GL-II-75) suggest they may have clinical potential. In humans, these ligands would bypass the reported GABA deficit in depression and simultaneously target mood and cognitive symptoms. Additional indications may include other conditions associated with reduced GABA signaling and with concurrent cognitive deficits and mood symptoms (schizophrenia, Alzheimer's disease, or normal age-related symptomatology).

\section{Acknowledgement}

We acknowledge the University of Wisconsin-Milwaukee's Shimadzu Laboratory for Advanced and Applied Analytical Chemistry. We thank the Milwaukee Institute of Drug Design. 


\section{Statement of Ethics}

Animal experiments conform to internationally accepted standards and have been approved by the appropriate institutional review body. Animal testing was conducted in accordance with the Canadian or US institutional animal care committee, and the Ethical Commission on Animal Experimentation of the Faculty of Pharmacy in Belgrade (carried out in accordance with the Directive 2010/63/EU).

\section{Disclosure Statement}

E.S., J.M.C., and M.S. are co-inventors or listed on a US provisional patent application that covers the described ligands modulating the function of GABA neurons. The other authors report no biomedical financial interests or potential conflicts of interest.

\section{Funding Sources}

E.S. received funding from the Brain \& Behavior Research Foundation, awarding NARSAD (\#25637), from the Campbell Family Mental Health Institute of CAMH, and from the Canadian Institute for Health Research. M.S. was funded by the Ministry of Education, Science and Technological Development, R. Serbia (Grant \#175076). J.M.C. received funding from the National Institute of Health (NIH: R01MH096463 and R01NS076517).

\section{Author Contributions}

T.D.P., G.L., A.V., M.B., J.M.C., M.S., and E.S. designed the study and wrote the manuscript. T.D.P., A.V., K.A.M., C.F., and A.S. ran the behavioral experiments using the different compounds. G.L., D.E.K., M.R.S., R.K., N.M.Z., L.A.A., and J.M.C. synthesized the new compounds and assessed their impact on locomotor activity. A.V., A.S., B.D.M., and M.S. performed the pharmacokinetic studies. J.L.F. performed the electrophysiology studies. P.S. performed the binding studies.

\section{References}

1 Lin LC, Sibille E. Somatostatin, neuronal vulnerability and behavioral emotionality. Mol Psychiatry. 2015 Mar;20(3):377-87.

2 Luscher B, Fuchs T. GABAergic control of depression-related brain states. Adv Pharmacol. 2015;73:97-144.

3 Nemeroff CB. The role of GABA in the pathophysiology and treatment of anxiety disorders. Psychopharmacol Bull. 2003;37(4):13346.

4 Gavilán MP, Revilla E, Pintado C, Castaño A, Vizuete ML, Moreno-González I, et al. Molecular and cellular characterization of the age-related neuroinflammatory processes occurring in normal rat hippocampus: potential relation with the loss of somatostatin GABAergic neurons. J Neurochem. 2007 Nov; 103(3):984-96.

5 Fuhrer TE, Palpagama TH, Waldvogel HJ, Synek BJ, Turner C, Faull RL, et al. Impaired expression of GABA transporters in the human Alzheimer's disease hippocampus, subiculum, entorhinal cortex and superior temporal gyrus. Neuroscience. 2017 May;351: 108-18.

6 Rajkowska G, O'Dwyer G, Teleki Z, Stockmeier CA, Miguel-Hidalgo JJ: GABAergic neurons immunoreactive for calcium binding proteins are reduced in the prefrontal cortex in major depression. Neuropsychopharmacology. 2007 Feb;32(2):471-82.

7 Price RB, Shungu DC, Mao X, Nestadt P, Kelly C, Collins KA, et al. Amino acid neurotransmitters assessed by proton magnetic resonance spectroscopy: relationship to treatment resistance in major depressive disorder. Biol Psychiatry. 2009 May;65(9):792-800.
8 Marenco S, Meyer C, van der Veen JW, Zhang Y, Kelly R, Shen J, Weinberger DR, Dickinson D, Berman KF: Role of gamma-amino-butyric acid in the dorsal anterior cingulate in ageassociated changes in cognition. Neuropsychopharmacology : official publication of the American College of Neuropsychopharmacology 2018; 43:2285-2291. https://doi. org/10.1038/s41386-018-0134-5.

9 Porges EC, Woods AJ, Edden RA, Puts NA, Harris AD, Chen $\mathrm{H}$, et al. Frontal GammaAminobutyric Acid Concentrations Are Associated With Cognitive Performance in Older Adults. Biol Psychiatry Cogn Neurosci Neuroimaging. 2017 Jan;2(1):38-44.

10 Möhler H. GABA(A) receptor diversity and pharmacology. Cell Tissue Res. 2006 Nov; 326(2):505-16.

11 Nardi AE, Cosci F, Balon R, Weintraub SJ, Freire RC, Krystal JH, et al. International Task Force on Benzodiazepines: The Prescription of Benzodiazepines for Panic Disorder: Time for an Evidence-Based Educational Approach. J Clin Psychopharmacol. 2018 Aug; 38(4):283-5.

12 Sigel E, Ernst M. The Benzodiazepine Binding Sites of GABAA Receptors. Trends Pharmacol Sci. 2018 Jul;39(7):659-71.

13 Gomez AF, Barthel AL, Hofmann SG. Comparing the efficacy of benzodiazepines and serotonergic anti-depressants for adults with generalized anxiety disorder: a meta-analytic review. Expert Opin Pharmacother. 2018 Jun; 19(8):883-94.

14 Parker GB, Graham RK. Determinants of Treatment-Resistant Depression: The Salience of Benzodiazepines. J Nerv Ment Dis. 2015 Sep;203(9):659-63.
15 Ghafari M, Falsafi SK, Szodorai E, Kim EJ, Li L, Höger H, et al. Formation of GABAA receptor complexes containing $\alpha 1$ and $\alpha 5$ subunits is paralleling a multiple T-maze learning task in mice. Brain Struct Funct. 2017 Jan; 222(1):549-61.

16 Smith KS, Engin E, Meloni EG, Rudolph U. Benzodiazepine-induced anxiolysis and reduction of conditioned fear are mediated by distinct GABAA receptor subtypes in mice. Neuropharmacology. 2012 Aug;63(2):250-8.

17 Behlke LM, Foster RA, Liu J, Benke D, Benham RS, Nathanson AJ, Yee BK, Zeilhofer HU, Engin E, Rudolph U: A Pharmacogenetic 'Restriction-of-Function' Approach Reveals Evidence for Anxiolytic-Like Actions Mediated by alpha5-Containing GABAA Receptors in Mice. Neuropsychopharmacology. 2016 Sep;41(10):2492-501.

18 Botta P, Demmou L, Kasugai Y, Markovic M, $\mathrm{Xu}$ C, Fadok JP, et al. Regulating anxiety with extrasynaptic inhibition. Nat Neurosci. 2015 Oct;18(10):1493-500.

19 Piantadosi SC, French BJ, Poe MM, Timić T, Marković BD, Pabba M, et al. Sex-Dependent Anti-Stress Effect of an a5 Subunit Containing GABAA Receptor Positive Allosteric Modulator. Front Pharmacol. 2016 Nov;7: 446.

20 Gill KM, Lodge DJ, Cook JM, Aras S, Grace AA. A novel a5GABA(A)R-positive allosteric modulator reverses hyperactivation of the dopamine system in the MAM model of schizophrenia. Neuropsychopharmacology. 2011 Aug;36(9):1903-11. 
21 Koh MT, Rosenzweig-Lipson S, Gallagher M. Selective GABA(A) a5 positive allosteric modulators improve cognitive function in aged rats with memory impairment. Neuropharmacology. 2013 Jan;64:145-52.

22 Hörtnagl H, Tasan RO, Wieselthaler A, Kirchmair E, Sieghart W, Sperk G. Patterns of mRNA and protein expression for $12 \mathrm{GABAA}$ receptor subunits in the mouse brain. Neuroscience. 2013 Apr;236:345-72.

23 Gill KM, Grace AA. The role of a5 GABAA receptor agonists in the treatment of cognitive deficits in schizophrenia. Curr Pharm Des. 2014;20(31):5069-76.

24 Nutt D. GABAA receptors: subtypes, regional distribution, and function. J Clin Sleep Med. 2006 Apr;2(2):S7-11.

25 McKernan RM, Rosahl TW, Reynolds DS, Sur C, Wafford KA, Atack JR, et al. Sedative but not anxiolytic properties of benzodiazepines are mediated by the GABA(A) receptor alpha1 subtype. Nat Neurosci. 2000 Jun;3(6): 587-92.

26 Rudolph U, Crestani F, Möhler H. GABA(A) receptor subtypes: dissecting their pharmacological functions. Trends Pharmacol Sci. 2001 Apr;22(4):188-94.

27 Clayton T, Poe MM, Rallapalli S, Biawat P, Savić MM, Rowlett JK, et al. A Review of the Updated Pharmacophore for the Alpha 5 GABA(A) Benzodiazepine Receptor Model. Int J Med Chem. 2015;2015:430248.

28 Bailey KR, Crawley JN. Anxiety-Related Behaviors in Mice; in Buccafusco JJ (ed): Methods of Behavior Analysis in Neuroscience. Boca Raton (FL), 2009.

29 Castagne V, Moser P, Porsolt RD. Behavioral Assessment of Antidepressant Activity in Rodents; in Buccafusco JJ (ed): Methods of Behavior Analysis in Neuroscience. Boca Raton (FL), 2009.

30 Vandesquille M, Krazem A, Louis C, Lestage P, Béracochéa D. S 18986 reverses spatial working memory impairments in aged mice: comparison with memantine. Psychopharmacology (Berl). 2011 Jun;215(4):709-20.

31 Stamenić TT, Poe MM, Rehman S, Santrač A, Divović B, Scholze P, et al. Ester to amide substitution improves selectivity, efficacy and kinetic behavior of a benzodiazepine positive modulator of GABAA receptors containing the $\alpha 5$ subunit. Eur J Pharmacol. 2016 Nov; 791:433-43.

32 Li G, Stephen MR, Kodali R, Zahn NM, Poe MM, Tiruveedhula VV, et al. Synthesis of chiral GABAA receptor subtype selective ligands as potential agents to treat schizophrenia as well as depression. ARKIVOC. 2018;2018(4): 158-83.

33 Richetto J, Labouesse MA, Poe MM, Cook JM, Grace AA, Riva MA, et al. Behavioral effects of the benzodiazepine-positive allosteric modulator SH-053-2' $\mathrm{F}-\mathrm{S}-\mathrm{CH}_{3}$ in an immunemediated neurodevelopmental disruption model. Int J Neuropsychopharmacol. 2015 Jan;18(4): 18

34 Alexeev M, Grosenbaugh DK, Mott DD, Fisher JL. The natural products magnolol and honokiol are positive allosteric modulators of both synaptic and extra-synaptic GABA(A) receptors. Neuropharmacology. 2012 Jun; 62(8):2507-14.

35 Namjoshi OA, Wang ZJ, Rallapalli SK, Johnson EM Jr, Johnson YT, $\mathrm{Ng} \mathrm{H}$, et al. Search for $\alpha 3 \beta_{2} /{ }_{3} \gamma 2$ subtype selective ligands that are stable on human liver microsomes. Bioorg Med Chem. 2013 Jan;21(1):93-101.

36 Obradović AL, Joksimović S, Poe MM, Ramerstorfer J, Varagic Z, Namjoshi O, et al. Sh-I$048 \mathrm{~A}$, an in vitro non-selective super-agonist at the benzodiazepine site of GABAA receptors: the approximated activation of receptor subtypes may explain behavioral effects. Brain Res. 2014 Mar;1554:36-48.

37 Lewter LA, Fisher JL, Siemian JN, Methuku KR, Poe MM, Cook JM, et al. Antinociceptive Effects of a Novel a2/a3-Subtype Selective GABAA Receptor Positive Allosteric Modulator. ACS Chem Neurosci. 2017 Jun;8(6): 1305-12.

38 Wafford KA, Thompson SA, Thomas D, Sikela J, Wilcox AS, Whiting PJ. Functional characterization of human gamma-aminobutyric acidA receptors containing the alpha 4 subunit. Mol Pharmacol. 1996 Sep;50(3):670-8.

39 Gustafsson S, Lindström V, Ingelsson $\mathrm{M}$, Hammarlund-Udenaes M, Syvänen S. Intact blood-brain barrier transport of small molecular drugs in animal models of amyloid beta and alpha-synuclein pathology. Neuropharmacology. 2018 Jan;128:482-91.

40 Divljaković J, Milić M, Namjoshi OA, Tiruveedhula VV, Timić T, Cook JM, et al. $\beta C C T$, an antagonist selective for $\alpha(1) \mathrm{GABA}(\mathrm{A})$ receptors, reverses diazepam withdrawal-induced anxiety in rats. Brain Res Bull. 2013 Feb;91:1-7.

41 Milić M, Divljaković J, Rallapalli S, van Linn ML, Timić T, Cook JM, et al. The role of al and $\alpha 5$ subunit-containing GABAA receptors in motor impairment induced by benzodiazepines in rats. Behav Pharmacol. 2012 Apr; 23(2):191-7.

42 Savić MM, Milinković MM, Rallapalli S, Clayton T Sr, Joksimović S, Van Linn M, et al. The differential role of alpha1- and alpha5-containing $\mathrm{GABA}(\mathrm{A})$ receptors in mediating diazepam effects on spontaneous locomotor activity and water-maze learning and memory in rats. Int J Neuropsychopharmacol. 2009 Oct;12(9):1179-93.

43 El Zahaf NA, Elhwuegi AS. The effect of GABAmimetics on the duration of immobility in the forced swim test in albino mice. Libyan J Med. 2014;9(1):23480.

44 Flugy A, Gagliano M, Cannizzaro C, Novara V, Cannizzaro G. Antidepressant and anxiolytic effects of alprazolam versus the conven- tional antidepressant desipramine and the anxiolytic diazepam in the forced swim test in rats. Eur J Pharmacol. 1992 Apr;214(2-3): 233-8.

45 Prévôt TD, Viollet C, Epelbaum J, Dominguez G, Béracochéa D, Guillou JL. sst2-receptor gene deletion exacerbates chronic stressinduced deficits: consequences for emotional and cognitive ageing. Prog Neuropsychopharmacol Biol Psychiatry. 2018 Aug;86:390400.

46 Griffin CE 3rd, Kaye AM, Bueno FR, Kaye $\mathrm{AD}$. Benzodiazepine pharmacology and central nervous system-mediated effects. Ochsner J. 2013;13(2):214-23.

47 Wang J, Guo Z, Fu Y, Wu Z, Huang C, Zheng $\mathrm{C}$, et al. Weak-binding molecules are not drugs?-toward a systematic strategy for finding effective weak-binding drugs. Brief Bioinform. 2017 Mar; 18(2):321-32.

48 Lister RG. The amnesic action of benzodiazepines in man. Neurosci Biobehav Rev. 1985; 9(1):87-94.

49 Zurek AA, Yu J, Wang DS, Haffey SC, Bridgwater EM, Penna A, et al. Sustained increase in a5GABAA receptor function impairs memory after anesthesia. J Clin Invest. 2014 Dec;124(12):5437-41.

50 Zanos P, Nelson ME, Highland JN, Krimmel SR, Georgiou P, Gould TD, et al. A Negative Allosteric Modulator for a5 Subunit-Containing GABA Receptors Exerts a Rapid and Persistent Antidepressant-Like Action without the Side Effects of the NMDA Receptor Antagonist Ketamine in Mice. eNeuro. 2017 Mar;4(1):4

51 Milić M, Timić T, Joksimović S, Biawat P, Rallapalli S, Divljaković J, et al. PWZ-029, an inverse agonist selective for $\alpha_{5}$ GABAA receptors, improves object recognition, but not water-maze memory in normal and scopolamine-treated rats. Behav Brain Res. 2013 Mar;241:206-13.

52 Martínez-Cué C, Martínez P, Rueda N, Vidal R, García S, Vidal V, et al. Reducing GABAA a5 receptor-mediated inhibition rescues functional and neuromorphological deficits in a mouse model of down syndrome. J Neurosci. $2013 \mathrm{Feb}$;33(9):3953-66.

53 Murray JD, Anticevic A, Gancsos M, Ichinose M, Corlett PR, Krystal JH, et al. Linking microcircuit dysfunction to cognitive impairment: effects of disinhibition associated with schizophrenia in a cortical working memory model. Cereb Cortex. 2014 Apr; 24(4):859-72.

54 Fee C, Banasr M, Sibille E. Somatostatin-Positive Gamma-Aminobutyric Acid Interneuron Deficits in Depression: Cortical Microcircuit and Therapeutic Perspectives. Biol Psychiatry. 2017 Oct;82(8):549-59.

55 Möhler H, Rudolph U. Disinhibition, an emerging pharmacology of learning and memory. F1000Res. 2017 Feb;6:6. 